OPEN ACCESS

Edited by:

Yunlong Yang,

Fudan University, China

Reviewed by:

Guichun Huang,

Nanjing University, China Yunjian Zhang,

First Affiliated Hospital of Sun Yat-sen

University, China

*Correspondence:

Laetitia Delort

laetitia.delort@uca.fr

Specialty section:

This article was submitted to Molecular and Cellular Oncology,

a section of the journal

Frontiers in Cell and Developmental

Biology

Received: 12 June 2020 Accepted: 25 November 2020

Published: 11 January 2021

Citation:

Delort L, Cholet J, Decombat C, Vermerie M, Dumontet $C$, Castelli FA, Fenaille $F$, Auxenfans $C$, Rossary $A$ and Caldefie-Chezet $F$ (2021) The Adipose Microenvironment

Dysregulates the Mammary Myoepithelial Cells and Could Participate to the Progression of Breast Cancer. Front. Cell Dev. Biol. 8:571948. doi: 10.3389/fcell.2020.571948

\section{The Adipose Microenvironment Dysregulates the Mammary Myoepithelial Cells and Could Participate to the Progression of Breast Cancer}

\author{
Laetitia Delort ${ }^{1 *}$, Juliette Cholet ${ }^{1}$, Caroline Decombat ${ }^{1}$, Marion Vermerie', \\ Charles Dumontet ${ }^{2}$, Florence A. Castelli ${ }^{3}$, François Fenaille ${ }^{3}$, Céline Auxenfans ${ }^{4}$, \\ Adrien Rossary ${ }^{1}$ and Florence Caldefie-Chezet ${ }^{1}$
}

\begin{abstract}
1 Université Clermont Auvergne, INRAE, UNH, ECREIN, Clermont-Ferrand, France, ${ }^{2}$ Université Lyon 1, INSERM U1052, CNRS 5286, Cancer Research Center of Lyon, Lyon, France, ${ }^{3}$ Université Paris-Saclay, CEA, INRAE, Département Médicaments et Technologies pour la Santé (DMTS), MetaboHUB, Gif-sur-Yvette, France, ${ }^{4}$ Banque de Tissus et de Cellules, Hôpital Edouard-Herriot, Lyon, France
\end{abstract}

Breast cancer is the most common cancer among women worldwide. Overweight and obesity are now recognized as established risk factors for this pathology in postmenopausal women. These conditions are also believed to be responsible for higher recurrence and mortality rates. Reciprocal interactions have been described between adipose and cancer cells. An adipose microenvironment favors a greater proliferation of cancer cells, their invasion and even resistance to anti-cancer treatments. In addition, the chronic low-grade inflammation observed in obese individuals is believed to amplify these processes. Among the cell types present in the breast, myoepithelial cells (MECs), located at the interface of the epithelial cells and the stroma, are considered "tumor suppressor" cells. During the transition from ductal carcinoma in situ to invasive cancer, disorganization or even the disappearance of MECs is observed, thereby enhancing the ability of the cancer cells to migrate. As the adipose microenvironment is now considered as a central actor in the progression of breast cancer, our objective was to evaluate if it could be involved in MEC functional modifications, leading to the transition of in situ to invasive carcinoma, particularly in obese patients. Through a co-culture model, we investigated the impact of human adipose stem cells from women of normal weight and obese women, differentiated or not into mature adipocytes, on the functionality of the MECs by measuring changes in viability, apoptosis, gene, and miRNA expressions. We found that adipose cells (precursors and differentiated adipocytes) could decrease the viability of the MECs, regardless of the original BMI. The adipose cells could also disrupt the expression of the genes involved in the maintenance of the extracellular matrix and to amplify the expression of leptin and inflammatory markers. miR-122-5p and miR132-3p could also be considered as targets for adipose cells. The metabolite analyses revealed specific profiles that may be involved in the growth of neoplastic cells. All of these perturbations could thus be responsible for the loss of tumor suppressor status of MECs and promote the transition from in situ to invasive carcinoma.

Keywords: myoepithelial cells, breast cancer progression, obesity, human adipose stem cells, mature adipocytes, miRNA, metabolomics 


\section{INTRODUCTION}

Breast cancer is the most common cancer among women, with more than 2.1 million new cases around the world and more than 626,000 deaths (Ferlay et al., 2019). Epidemiological studies have confirmed the association between overweight and obesity with a higher risk of postmenopausal breast cancer $(R R=1.12,95 \%$ confidence interval $[95 \% \mathrm{CI}]=1.09-1.15)$ (World Cancer Research Fund [WCRF], 2017), larger tumors, positive lymph-node status and reduced outcomes, regardless of menopausal status (Dignam et al., 2003; Picon-Ruiz et al., 2017). To understand the link between obesity and breast cancer, a large number of studies have been focused on the adipose tumor microenvironment and showed its importance in the development, growth and progression of cancer. Reciprocal interactions have been revealed between breast cancer cells and their adipose microenvironment, particularly in obese situations. The adipose microenvironment, mainly consisting of adipocytes as well as adipose stem cells, fibroblasts, endothelial and immune cells, is able to promote angiogenesis (Bougaret et al., 2017; Quail and Dannenberg, 2019; Yadav et al., 2020) and to reduce the efficiency of anticancer treatments, such as tamoxifen (Bougaret et al., 2018; Delort et al., 2019). Adipose tissue is considered to be an endocrine organ capable of secreting soluble factors (growth factors, cytokines, adipokines, proteases and vascular stimulation factors) that can act on surrounding cells and on the composition of the extracellular matrix (Walter et al., 2009). The mammary stroma can undergo phenotypic and functional changes in order to be active and provide a favorable environment for the development of the mammary tumor (Place et al., 2011). Knowledge of the underlying pathophysiological mechanisms could be beneficial in the management of overweight patients.

Abbreviations: ADIPOQ, adiponectin; ADIPOR1, Adiponectin Receptor 1; ADIPOR2, Adiponectin Receptor 2; AKT1, AKT Serine/Threonine Kinase 1; BAX, BCL2 Associated X; BCAA, Branched-Chain Amino Acid; BMI, Body Mass Index; CASP9, Caspase 9; CCNB1, Cyclin B1; CCND1, Cyclin D1; CDH1, Cadherin 1; CI, Confidence Interval; CM, Conditioned Media; CTNNB1, Catenin Beta 1; CXCL12, C-X-C Motif Chemokine Ligand 12; CYP19A1, Cytochrome P450 Family 19 Subfamily A Member 1; DCIS, Ductal Carcinoma In Situ; ECM, Extra-Cellular Matrix; ER, Estrogen Receptor; ESR1, Estrogen Receptor 1; ESR2, Estrogen Receptor 2; FGFR1, Fibroblast Growth Factor Receptor 1; FN1, Fibronectin 1; GAPDH, Glyceraldehyde-3-Phosphate Dehydrogenase; GUSB, Beta-Glucuronidase; hASCs, human Adipose Stem Cells; hASC20, human Adipose Stem Cells from women of normal weight; hASC30, human Adipose Stem Cells from obese women; hMAD, human Multipotent Adipose cell line; hMAD\#, human Multipotent Adipose cell differentiated in mature adipocytes; HPRT1, Hypoxanthine Phosphoribosyltransferase 1; HSPG2, Heparan Sulfate Proteoglycan 2; IDC, Invasive Ductal Cancer; IL6, Interleukin 6; KRT5, Keratin 5; LAMA1, Laminin Subunit Alpha 1; LAMB1, Laminin Subunit Beta 1; LEP, Leptine; LEPR, Leptine Receptor; MA, Mature Adipocyte; MA20, Mature Adipocyte from women of normal weight; MA30, Mature Adipocyte from obese women; MECs, MyoEpithelial Cells; MKI67, Marker of proliferation Ki 67; MMP2, Matrix Metallopeptidase 2; MMP3, Matrix Metallopeptidase 3; MMP9, Matrix Metallopeptidase 9; MMP10, Matrix Metallopeptidase 10; MMP14, Matrix Metallopeptidase 14; MYBL2, MYB Proto-Oncogene Like 2; MYC, MYC ProtoOncogene; PTEN, Phosphatase And Tensin Homolog; PTGS2, ProstaglandinEndoperoxide Synthase 2; RR, Relative Risk; SERPINE1, Serpin Family E Member 1; SERPINB5, Serpin Family B Member 5; TGFB1, Transforming Growth Factor Beta 1; THBS1, Thrombospondin 1; TIMP1, TIMP Metallopeptidase Inhibitor 1; TNF, Tumor Necrosis Factor; TP53, Tumor Protein P53; TP63, Tumor Protein
Breast tissue is composed of myoepithelial cells (MECs). These cells are little studied mammary cell types but which play a major role in the normal structure of the breast. MECs are hybrid of both smooth muscle and epithelial cells that are present around the acini of certain exocrine glands, such as the mammary glands and whose contraction results in the expulsion of the secretion product from the glandular acini (Adriance et al., 2005). These cells play a role in basement membrane formation and lactation through the expression of type IV collagen, laminin, actin and oxytocin receptors. MECs constitute an almost continuous layer of cells that surround luminal epithelial cells, separating them from the basement membrane and the stroma and limiting tumor invasion. MECs can be detected by specific markers (p63, CD10, $\alpha$-smooth muscle actin) and constitute a major criterion for pathologists to distinguish between ductal carcinoma in situ (DCIS), for which epithelial cells are separated from the stroma by this continuous layer of MECs, and invasive ductal cancer (IDC), for which cancer cells are in direct contact with stroma cells (Allinen et al., 2004; Polyak and $\mathrm{Hu}, 2005$ ). Data suggest that MECs are critical for the maintenance of DCIS and the invasion process (Sirka et al., 2018).

MECs are referred to as "tumor suppressors." In addition to forming a physical barrier against the invasion of tumor cells, studies have shown that they strongly express extracellular matrix proteins (collagen, laminin A, fibronectin, osteonectin, etc.), proteins involved in angiogenesis (thrombospondin-1, plasminogen) and protease inhibitors (Polyak and $\mathrm{Hu}, 2005$ ). They have the ability to inhibit the growth, invasion and angiogenesis of breast cancer cells, this means the loss of CD44 and the expression of protease inhibitors. These cells also have anti-angiogenic, anti-proliferative and anti-invasive properties through the expression of proteins known for their tumor suppressing effect (p63, p73, maspine). They are also involved in the polarity of the luminal epithelial cells via specific desmosomal proteins and laminin-1 release (Allen et al., 2014).

Modifications of gene expression have been observed in the case of a DCIS compared to a normal myoepithelium. Proteases (cathepsin F, K, L; MMP2, PRSSAA), protease inhibitors (thrombospondin-2, SERPIN-1, cystatin C, TIMP3) and collagen are strongly overexpressed at the MEC level in the case of DCIS, suggesting a major role for these cells in extracellular matrix remodeling (Allinen et al., 2004). Our team has already demonstrated that MECs express high levels of adiponectin in breast tissue adjacent to tumor samples, an adipokine known to have antiproliferative activities, and to not express leptin, an adipokine with procarcinogenic properties. Thus, these cells, through adiponectin secretion, would have the ability to protect normal epithelial cells and inhibit the proliferation of breast cancer cells through a paracrine effect (Jarde et al., 2008). Co-culture experiments have shown that MECs are able to decrease the expression of metalloproteinases by mammary cancer cells, even in the presence of fibroblasts,

P63; VEGFA, Vascular Endothelial Growth Factor A; VIM, Vimentin; WT1, WT1 Transcription Factor. 
thus confirming the dominance and the importance of these MECs in invasion. In addition, these cells have increased antiproliferative and anti-invasive capacities in the presence of tamoxifen, following an increase in maspine secretion, and in the production of inducible nitric oxide synthase (iNOS). These effects are reportedly mediated by the estrogen receptor (ER), as MECs express ER $\alpha$ and not ER $\beta$ (Jones et al., 2003). Few studies have focused on the impact of obesity on MECs. Chamberlin et al. (2017) have shown that obesity was able to increase the ratio of luminal to basal/myoepithelial cells in both human samples and a model of obese mice, confirming the positive correlation between increased BMI and the reduced number of MECs. Their model of obese mice revealed that the continuous layer of MECs in normal mammary gland was discontinued in obese mice and similar observations were made in human samples (Chamberlin et al., 2017).

For all these reasons, we hypothesized that the mammary adipose tumor microenvironment could be involved in the functional modifications of MECs, reducing/inhibiting their tumor-suppressive capacities and disrupting the spatial organization of MECs. This would lead to favor the invasion of cancer cells and the transition from DCIS to IDC, particularly in an obese situation. Using a co-culture model, we studied the impact of human adipose cells from women of normal weight and obese women on the functionality of the MECs by measuring their impact on viability, apoptosis and gene expression. The role of miRNAs was also evaluated in our model. Our study revealed that adipose cells (adipose precursors and mature adipocytes) could be able of modifying the functional characteristics of the MECs and these effects could be mediated by leptin and inflammatory markers.

\section{MATERIALS AND METHODS}

\section{Co-culture Experiments Cell Culture}

\section{Myoepithelial Cells (MECs)}

Hs578Bst normal myoepithelial breast cell line was obtained from ATCC and cultured in DMEM/F12 (Gibco, Thermo Fisher Scientific, Waltham, United States) supplemented with EGF (30 ng/mL, Sigma-Aldrich, Saint Quentin Fallavier, France), fetal bovine serum (10\%), L-glutamine (1\%) and gentamycin (50 $\mu \mathrm{g} / \mathrm{mL}$ ) (Thermo Fisher Scientific).

\section{Adipose Cells}

The human multipotent adipose cell line (hMAD) is a kind gift from Charles Dumontet (University Lyon 1, Lyon, France; INSERM U1052, CNRS 5286, Cancer Research Center of Lyon, Lyon, France). Human adipose stem cells (hASCs) were kindly provided by the Cell and Tissue Bank (Hôpital EdouardHerriot, Lyon, France). hASCs were obtained from patients undergoing surgery for cosmetic purposes without associated pathology according to Helsinki declaration from anonymous healthy donors. Surgical residue was harvested according to French regulation including declaration to research ministry (DC $\mathrm{n}^{\circ} 2008162$ ) and procurement of written informed consent from the patient. hASCs were extracted from subcutaneous adipose tissue from women undergoing optimized liposuction and who were of normal weight (hASC20: human adipose stem cells from women of normal weight) or obese (hASC30: human adipose stem cells from obese women). hASCs were extracted (Mojallal et al., 2008) using a $3 \mathrm{~mm}$ cannula according to ethical and safety guidelines as approved by the local IRB and as described by Björntorp (Lequeux et al., 2009). Four different strains were obtained from women of normal weight (BMI comprised between 18 and 22) and 6 from obese women (BMI > to 30).

\section{Differentiation of hASCs}

hMAD cells and hASCs were seeded at confluence $(33,500$ cells $/ \mathrm{cm}^{2}$ ) in a differentiation medium consisted of DMEM/F12 (1:1) supplemented with $10 \% \mathrm{FBS}$, hydrocortisone $(25 \mu \mathrm{g} / \mathrm{mL})$, insulin $(3.5 \mathrm{mg} / \mathrm{mL})$, T3 $(6.5 \mu \mathrm{g} / \mathrm{mL})$, dexamethasone (980 $\mu \mathrm{g} / \mathrm{mL})$, rosiglitazone $(1.78 \mathrm{mg} / \mathrm{mL})$, IBMX (100 mg/mL, only the first 3 days), gentamycin $(50 \mu \mathrm{g} / \mathrm{mL})$. The medium was replaced every 2 days. Mature adipocytes (MAs) were obtained after 12 days of differentiation (hMAD\#, MA20, MA30) (Bougaret et al., 2017). The effectiveness of differentiation as well as the ability of hASCs to maintain a metabolism representative of their tissue of origin (collected from women of normal weight or obese women) has been previously validated (Bougaret et al., 2017).

All the cells used were under mycoplasma-free conditions and cultured in a $5 \% \mathrm{CO}_{2}$-humidified incubator at $37^{\circ} \mathrm{C}$.

\section{Co-culture Between MECs and Adipose Cells}

Interactions between MECs and adipose cells were evaluated using a co-culture system (Transwell culture system, porosity $0.4 \mu \mathrm{m})$. MECs were seeded at the bottom of wells $(5,000$ cells/well) and co-cultured with either hASCs (hMAD cells or hASCs) seeded in inserts (5,000 cells/inserts) or hASCs previously differentiated into MAs (hMAD\#, MA) in DMEM/F12 medium supplemented with FBS (10\%) and glutamine (1\%). After $72 \mathrm{~h}$ of incubation, the culture medium was substituted with a resazurin solution $(25 \mu \mathrm{g} / \mathrm{mL})$, which in the presence of metabolically active cells is oxidized to a pink fluorescent resorufin product and whose fluorescence intensity is proportional to the number of viable cells $(\mathrm{Exw}=530 \mathrm{~nm}$ and Emw $=590 \mathrm{~nm}$, Fluoroskan Ascent FL ${ }^{\circledR}$, Thermo Fisher Scientific). Experiments were realized at least three times for the study of hMAD cell line and at least eight times for the hASCs and MAs. Results were expressed as percentage of growth \pm SEM.

\section{Culture With Conditioned Media (CM)}

Conditioned media (CM) were collected after $48 \mathrm{~h}$ of culture of hASCs or MAs in DMEM/F12 supplemented with FBS (10\%) and glutamine $(1 \%)$ and kept under nitrogen atmosphere at $-80^{\circ} \mathrm{C}$. To assess the specific role of adipose secretome, MECs were exposed to CM (dilution 1:1 in fresh complete adipose cell media) and the viability was measured after $72 \mathrm{~h}$ with the resazurine test (3 independent experiments) (Bougaret et al., 2018).

\section{Apoptosis Assay}

Following viability assays, MECs were washed with phosphate buffered saline (PBS), recovered by centrifugation at $1,000 \mathrm{~g}$ 
for $5 \mathrm{~min}$ at room temperature (RT), and resuspended in $40 \mu \mathrm{L}$ of annexin $\mathrm{V}$ binding buffer $(140 \mathrm{~mm} \mathrm{NaCl}, 10 \mathrm{~mm}$ HEPES/NaOH, $2.5 \mathrm{~mm} \mathrm{CaCl}$ ). The cell suspension was stained with $5 \mu \mathrm{L}$ of annexin V-FITC and $5 \mu \mathrm{L}$ of propidium iodide (PI), and incubated for $15 \mathrm{~min}$ at RT in the dark. After the addition of PBS and a centrifugation at $1,000 \mathrm{~g}$ for $5 \mathrm{~min}$ at RT, cells were resuspended in $50 \mu \mathrm{L}$ of annexin $\mathrm{V}$ binding buffer. Stained cells were then analyzed on a Cellometer K2 image cytometer (Nexcelom Bioscience, Lawrence, MA, United States). Data were expressed as percentage of live cells, \% cells in early or late apoptosis and \% of necrotic cells. Experiments were realized three times.

\section{Quantitative Real-Time PCR (qPCR) Assays}

Total RNA was extracted from co-cultured or not MECs with TRIZOL reagent (Invitrogen, Thermo Fisher Scientific). After the evaluation of the quantity and purity (NanoDrop 2000, Thermo Fisher Scientific), DNase treatment (DNase I Amplification grade, Invitrogen) and cDNAs retrotranscription (HighCap cDNA RT Kit RNAse inhib, Invitrogen) were made according to the manufacturer's recommendations. qPCR were performed on plates designed by Applied Biosystems (TaqMan ${ }^{\circledR}$ Array 96 well Fast Plate, Customformat 48) using SDS7900HT automaton (Applied Biosystems, Thermo Fisher Scientific) with TaqMAN ${ }^{\circledR}$ (Applied Biosystems). The analysis was conducted on 44 genes and 4 references genes with TaqMAN ${ }^{\circledR}$ Array Fast Plates (18S, GAPDH, HPRT1, GUSB, LEP, LEPR, ADIPOQ, ADIPOR1, ADIPOR2, ESR1, ESR2, CDH1, MMP2, MMP3, MMP9, MMP14, IL6, TNF, VEGFA, MYC, AKT1, BAX, CCND1, TP53, CYP19A1, CTNNB1, PTEN, TP63, SERPINB5, TIMP1, SERPINE1, THBS1, FGFR1, MMP10, TGFB1, HSPG2, LAMA1, LAMB1, KRT5, VIM, FN1, PTGS2, CXCL12, MYBL2, CASP9, CCNB1, WT1, MKI67). Genes were considered significantly expressed and their transcript measurable if their corresponding $\mathrm{Ct}$ value was less than 35. Each sample was normalized to endogenous reference genes. The relative quantification method $\left(R Q=2^{-\Delta \Delta C T}\right)$ was used to calculate the relative gene expression of given samples with $\Delta \Delta \mathrm{CT}=[\Delta \mathrm{CT}$ (sample1) $-\Delta \mathrm{CT}$ (sample2) $]$ and $\Delta \mathrm{CT}=[\mathrm{CT}($ target gene $)-$ geometric mean $\mathrm{CT}$ (reference genes)]. Paired $t$-tests were used for comparisons of gene expression levels with at least two valid pairs of values. Control of the false discovery rate due to multiple testing was done according to Benjamini-Hochberg method for each comparison separately. Using $\triangle \mathrm{CT}$ values, gene expression was plotted as a heatmap, paired with a two-way hierarchical cluster analysis (package "gplots") in R version 3.5.0. Three independent experiments were performed.

\section{MiRNAs}

miR expression was determined using TaqMan ${ }^{\circledR}$ Advanced miRNA Assays (SDS7900HT Fast Real-Time PCR Systems, Applied Biosystems, Thermo Fisher Scientific) according to the manufacturer's recommendations. miRNAs were first extracted with NucleoSpin miRNA and RNA purification (Macherey-Nagel, Dürer, Germany). All other steps were performed using the TaqMan ${ }^{\circledR}$ Advanced miRNA Assays. Briefly, miRNAs were modified by extending the 3' end of the transcript through a poly $(\mathrm{A})$ addition, then lengthening the 5 ' end by adaptor ligation. Then modified miRNAs were reverse transcribed (TaqMan ${ }^{\circledR}$ Advanced miRNA cDNA Synthesis Kit, Life Technologies) followed by an amplification to increase uniformly the amount of cDNA for all miRNAs $(5 \mathrm{~min}$ at $95^{\circ} \mathrm{C}$, followed by 14 cycles with $3 \mathrm{~s}$ at $95^{\circ} \mathrm{C}$ and $30 \mathrm{~s}$ at $60^{\circ} \mathrm{C}$ and finally $10 \mathrm{~min}$ at $99^{\circ} \mathrm{C}$ ). The PCR was then performed (10 min at $92^{\circ} \mathrm{C}$, followed by 40 cycles with $1 \mathrm{~s}$ at $95^{\circ} \mathrm{C}$ and 20 $s$ at $\left.60^{\circ} \mathrm{C}\right)$. miRNAs were considered significantly detected if their corresponding $\mathrm{Ct}$ value was less than 32. Two exogenous controls (ath-miR159a and cel-miR-39-3p) non expressed in human permitted to validate experiments. A global mean normalization was used to normalize data. Gene expression was measured using the comparative $\mathrm{Ct}(\Delta \Delta \mathrm{Ct})$ method of relative quantitation. The analysis workflow was made by DataAssist software (Applied Biosystems). Four independent experiments were performed. Using DCT values, gene expression was plotted as a heatmap, paired with a two-way hierarchical cluster analysis (package "gplots") in $\mathrm{R}$ version 3.5.0. The predicted miRNA target were determined using mirPath v.3 from DIANA TOOLS bioinformatics resources through gene ontology biological process (GO) terms and The Kyoto Encyclopedia of Genes and Genomes (KEGG) pathway terms (Vlachos et al., 2015).

\section{UNTARGETED METABOLOMICS BY LIQUID CHROMATOGRAPHY COUPLED TO HIGH-RESOLUTION MASS SPECTROMETRY}

In order to identify the molecules potentially responsible for the effect on the MECs, the analysis of culture media of hASCs and MAs differentiated from hASCs from women of normal weight and obese women was carried out by mass spectrometry-based untargeted metabolomics.

\section{Chemicals and Reagents}

All analytical grade reference compounds were from SigmaAldrich (Saint Quentin Fallavier, France). The standard mixtures used for the external calibration of the spectrometer (Calmix-positive, for the positive ion mode, consisting of caffeine, L-methionyl-arginyl-phenylalanyl-alanine acetate, and Ultramark 1621, and Calmix-negative, for the negative ion mode, consisting of the same mixture plus sodium dodecyl sulfate and sodium taurocholate) were from Thermo Fisher Scientific (Courtaboeuf, France). Acetonitrile (ACN) was from SDS (Peypin, France), formic acid from Merck (Briare-le-Canal, France), methanol from VWR Chemicals (Fontenay-sousBois, France) and deionized water from Biosolve chemicals (Dieuse, France).

\section{Metabolite Extraction}

After thawing at room temperature, culture cell supernatants were immediately processed. Samples $(50 \mu \mathrm{L})$ were deproteinized in microcentrifuge tubes by adding $200 \mu \mathrm{L}$ of methanol, 
thoroughly vortexed, incubated in an ultrasonic bath for $5 \mathrm{~min}$ and then left on ice for $90 \mathrm{~min}$. After vortexing, the samples were centrifuged at $20,000 \mathrm{~g}$ for $15 \mathrm{~min}$ at $4^{\circ} \mathrm{C}$. The supernatant was then evaporated to dryness under a nitrogen stream at $30^{\circ} \mathrm{C}$ using a Turbovap (Caliper Life Science Inc., Roissy, France). Then, $150 \mu \mathrm{L}$ of either $\mathrm{H}_{2} \mathrm{O}$ :ACN (95:5, v/v), with $0.1 \%$ formic acid or $10 \mathrm{mM}$ ammonium carbonate $\mathrm{pH}$ 10.5:ACN (40:60, $\mathrm{v} / \mathrm{v})$ were added to the residue to reconstitute the culture cell extracts for RP and HILIC analyses (see below), respectively. The tubes were vortexed again and incubated in an ultrasonic bath for $5 \mathrm{~min}$ and centrifuged for another $10 \mathrm{~min}$. A volume of $95 \mu \mathrm{L}$ of the supernatant was transferred to $0.2 \mathrm{~mL}$ vials. Internal standard solution $(5 \mu \mathrm{L}$; mixture of 9 authentic chemical standards covering the mass range of interest: 13C-glucose, $15 \mathrm{~N}$ aspartate, ethylmalonic acid, amiloride, prednisone, metformin, atropine sulfate, colchicine, imipramine) was added to all samples in order to check for consistency of analytical results in terms of signal and retention time stability throughout the experimental batch. In addition, a quality control (QC) sample was obtained by pooling $20 \mu \mathrm{L}$ of each sample and was injected every five samples in order to evaluate the signal variations of each metabolite.

\section{Liquid Chromatography Coupled to High-Resolution Mass Spectrometry (LC-HRMS)}

Metabolite profiling was performed using a combination of two complementary chromatographic columns, a Hypersil GOLD C8 (RP, $1.9 \mu \mathrm{m}, 2.1 \mathrm{~mm} \times 150 \mathrm{~mm}$ column, Thermo Fisher Scientific), and a Sequant ZICpHILIC $5 \mu \mathrm{m}, 2.1 \times 150 \mathrm{~mm}$ (HILIC) (Merck, Darmstadt, Germany) that were maintained at $30^{\circ} \mathrm{C}$ and $15^{\circ} \mathrm{C}$, respectively. Both columns were equipped with an on-line prefilter (Thermo Fisher Scientific). Experimental settings for each LC-HRMS condition are described below.

Mobile phases for the RP column were $100 \%$ water in $\mathrm{A}$ and $100 \% \mathrm{ACN}$ in $\mathrm{B}$, both containing $0.1 \%$ formic acid. Regarding HILIC, phase A consisted of an aqueous buffer of $10 \mathrm{mM}$ ammonium carbonate in water adjusted to $\mathrm{pH} 10.5$ with ammonium hydroxide, whereas pure ACN was used as solvent B. Chromatographic elutions were achieved under gradient conditions as follows:

(i) RP-based system: the flow rate was set at $500 \mu \mathrm{L} / \mathrm{min}$. The elution consisted of an isocratic step of $2 \mathrm{~min}$ at $5 \%$ phase $\mathrm{B}$, followed by a linear gradient from 5 to $100 \%$ of phase $\mathrm{B}$ for the next $11 \mathrm{~min}$. These proportions were kept constant for $12.5 \mathrm{~min}$ before returning to $5 \% \mathrm{~B}$ for $4.5 \mathrm{~min}$.

(ii) HILIC-based system: the flow rate was $200 \mu \mathrm{L} / \mathrm{min}$. Elution started with an isocratic step of $2 \mathrm{~min}$ at $80 \% \mathrm{~B}$, followed by a linear gradient from 80 to $40 \%$ of phase B from 2 to $12 \mathrm{~min}$. The chromatographic system was then rinsed for $5 \mathrm{~min}$ at $0 \% \mathrm{~B}$, and the run ended with an equilibration step of $15 \min (80 \% \mathrm{~B})$.

LC-HRMS analyses were performed using an Ultimate U3000 liquid chromatography system coupled to an Exactive mass spectrometer from Thermo Fisher Scientific fitted with an electrospray (ESI) source and operated in the positive and negative ion modes for metabolite separations on $\mathrm{C} 18$ and ZIC-pHILIC columns, respectively. The software interface was Xcalibur (version 2.1, Thermo Fisher Scientific). The mass spectrometer was externally calibrated before each analysis in both ESI polarities using the manufacturer's predefined methods and recommended calibration mixtures provided by the manufacturer.

The Exactive mass spectrometer was operated with a capillary voltage set at $-3 \mathrm{kV}$ in the negative ionization mode and at $5 \mathrm{kV}$ in the positive ionization mode, and with a capillary temperature set at $280^{\circ} \mathrm{C}$. The sheath gas and the auxiliary gas pressures were set at 60 and 10 arbitrary units with nitrogen gas, respectively. The mass resolution power of the analyzer was 50,000 at $\mathrm{m} / \mathrm{z}$ 200 (full width at half maximum) for singly charged ions. The detection was achieved from $m / z 85$ to 1,000 for RP conditions in the positive ionization mode and from $\mathrm{m} / z 75$ to 1,000 for HILIC conditions in the negative ionization mode.

\section{Data Treatment and Handling}

All raw data were first manually inspected using the Qualbrowser module of Xcalibur version 2.1 (Thermo Fisher Scientific). Raw files were first of all converted to mzXML format using MSConvert software. Automatic peak detection and integration were performed using the XCMS software package (W4M platform; Giacomoni et al., 2015)1.

\section{Metabolite Annotation and Identification}

Features were annotated by using our spectral database according to accurately measured masses and chromatographic retention times (Boudah et al., 2014). Confirmation of metabolite annotation was then accomplished by running additional LC-MS/MS experiments using an Ultimate chromatographic system combined with a Q-Exactive mass spectrometer (Thermo Fisher Scientific) under non-resonant collisioninduced dissociation conditions using higher-energy C-trap dissociation (HCD). To be identified, ions had to match at least two orthogonal criteria (accurately measured mass, isotopic pattern, MS/MS spectrum and retention time) to those of an authentic chemical standard analyzed under the same analytical conditions, as proposed by the Metabolomics Standards Initiative (Sumner et al., 2007).

\section{Statistical Analyses}

Chromatographic peak areas contained in the two filtered and processed XCMS data matrices (i.e., RP-UHPLC-HRMS with MS detection in positive ESI modes, and HILIC-HPLCHRMS with MS detection in the negative ESI mode) were statistically analyzed using both multivariate (PCA, PLS-DA) and univariate statistical tests available on the W4M platform (see text footnote 1) in order to identify pertinent metabolites. The significant metabolites were imported into the freely available online MetExplore tool (Cottret et al., 2018) for metabolic pathway enrichment.

\footnotetext{
${ }^{1}$ https://galaxy.workflow4metabolomics.org
} 


\section{RESULTS}

\section{Adipose Precursors and Differentiated Adipose Cells Are Able to Adversely Influence the Viability of Myoepithelial Cells Whatever the BMI}

Our different experiments highlight the influence of adipose cells on the functionality of MECs.

Adipose cells, whether derived from a lineage (hMAD) or from primary cells (hASCs) seemed to decrease the viability of the MECs (Figure 1A). In addition, it appears that adipocyte precursors (hMAD and hASCs) play a role as important as differentiated adipocytes (hMAD\# and MAs). Indeed, when the MECs were co-cultured with hASCs (hMAD cell line or hASCs from healthy women), the viability of MECs was reduced $(-22 \% p<0.05$ and $-10 \%, p<0.01$ with hMAD and hASCs, respectively). Mature adipocytes (hMAD\# or MAs) appeared to have a similar impact on the viability of the MECs compared to the precursors $(-11 \%, p<0.001)$. The evaluation of apoptosis by image cytometry (Figure 1B) showed a slight increase of the percentage of apoptotic cells when the MECs were co-cultured with hMAD. When the MECs were only exposed to the secretome (Figure 1C), the same trend was observed, with a significant decrease in the viability only in the presence of hASC secretions.

The influence of obesity was evaluated using hASCs from both women of normal weight (hASC20) and obese women (hASC30), differentiated into MAs (MA20, MA30) (Figure 2). Cells from women of normal weight and obese women, whether hASCs or MAs, appeared to decrease the viability of the MECs in the same proportions $(-12 \%$ with hASC20; $-8 \%$ with hASC $30 ;-14 \%$ with MA20, $p<0.01 ;-8 \%$ with MA30, ns) (Figure 2A). Surprisingly, only the MA30-induced decrease was not significant in our study. When the MECs were only exposed to adipose secretions (Figure 2B). The only significant effect was found with secretions of hASCs from the obese women $[-22 \%$ with MC(hASC30)].

\section{The Adipose Microenvironment Is Able to Disrupt the Expression of the Genes Involved in the Maintenance of the Extracellular Matrix. Leptin and Inflammatory Genes Also Seem to Be Central Regulating These Disturbances}

We next sought to identify the underlying mechanism by which adipose cells could act on MECs by first focusing on gene expression modifications. We investigated the modifications of the genes involved in the maintenance of the extracellular matrix (MMP2, MMP3, MMP9, MMP14, SERPINB5, SERPINE1, FGFR1, MMP10, HSPG2, LAMA1, $L A M B 1, V I M, F N 1$ ), angiogenesis (THBS1, TIMP1, CDH1, VEGFA), cytokine/hormonal pathways (LEP, LEPR, ADIPOQ, ADIPOR1, ADIPOR2, ESR1, ESR2, CYP19A1), inflammation (IL6, TNF, PTGS2), cell cycle/proliferation/apoptosis (MYC, AKT1, BAX, CCND1, TP53, CTNNB1, PTEN, TGFB1, KRT5, CXCL12, MYBL2, CASP9, CCNB1, WT1, MKI67).
Hierarchical clustering enabled a clear discrimination of the MECs co-cultured, or not, with hASCs or MAs, with under-expressed genes (red font), over-expressed genes (green font) or non-modified genes (yellow font) (Figure 3). The cell type appeared to be more discriminant than the BMI of the cells. The hierarchical analysis highlighted a first cluster of genes similarly expressed in the MECs and in the MECs co-cultured with hASCs (Cluster 1: AdipoR1, MMP2, BAX, PTEN, CASP9, AdipoR2 over-expressed in green font) compared to the cells co-cultured with MAs (red font). A second cluster presented the inverse observation, with a group of genes over-expressed in the MECs co-cultured with MAs (Cluster 2: Leptin, leptin receptor, CYP191A1, PTGS2). A third cluster composed of MMP10, MMP14, vimentine, serpine1, CXCL12 and CCNB1, could also be identified wherein their expression in the MECs is clearly up-regulated compared to the co-cultured cells, whatever the type and BMI of the adipose cells.

The gene expressions were first compared between the MECs co-cultured with adipose cells, and non co-cultured cells (Figure 4A). The major role of the MECs is their involvement in the integrity of the basement membrane by producing fibronectin or laminin for example. Laminin constitutes a key element in the polarity maintenance of epithelial cells and could be a marker of MEC integrity. In our model, a tendency to decrease laminin expression was observed when MECs were co-cultivated with hASCs. The major genes involved in the maintenance of the matrix (Serpine1, MMP14, MMP10) were significantly under-expressed when the MECs were co-cultured with adipose cells (hASCs or MAs), except for fibronectin whose expression was increased in the presence of mature adipocytes $(R Q=1.7, p<0.01)$. Among the studied ECMdegrading proteases (MMP2, 3, 9, 10, 14), the decrease in the MMP10 gene expression when the MECs were co-cultured with hASCs, was the only observed significant modification $(R Q=0.4, p=0.026$ MECs co-cultured with hASCs vs. MECs; $R Q=0.5, p=0.07$ MECs co-cultured with MAs vs. MECs). However, for the other proteases, it is possible to note a general downward trend. When the effect of obesity was studied (Figure 4B), the expression of LAMB1, Serpine1, $M M P 14, M M P 10$ appeared to decrease but a general downward trend could be noted.

Almost all of the studied genes involved in cell cycle, proliferation, apoptosis and even angiogenesis were not altered in the MECs co-cultured with adipose cells, suggesting that these genes were not responsible for the decrease in the viability previously observed. It seemed that the expression of tumor suppressor genes (SerpineB5, MYC, P53, WT1, TGFB1, CCNB1, MYBL2) were not modified, suggesting that the MECs preserve their tumor suppressor function.

On the contrary, important modifications in the expression of genes coding for cytokines/hormones or involved in inflammatory processes have been highlighted. For example, leptin expression appeared quadrupled in the MECs in the presence of adipose precursor cells $(R Q=4.2, p=0.076)$ and increased by a factor of 52 with 

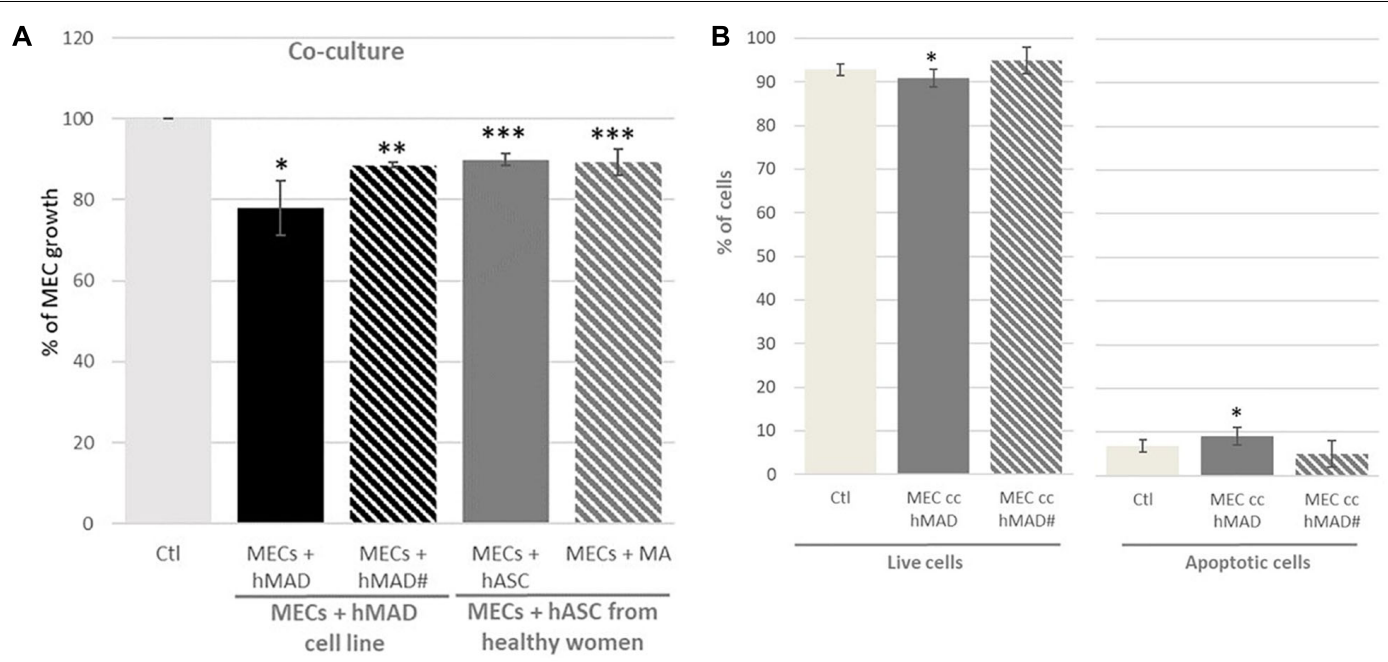

C 120

Conditioned Media

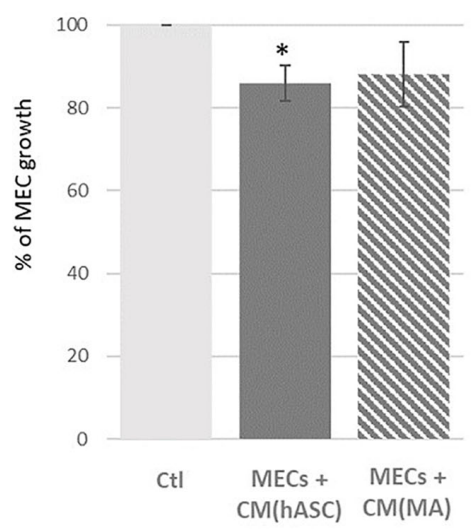

FIGURE 1 | Percentage of myoepithelial cell (MEC) viability and apoptosis when they were co-cultured with adipose cells or adipose secretome. (A) MECs were co-cultured for $72 \mathrm{~h}$ with the human multipotent adipose derived cell line (hMAD) or human adipose stem cells (hASCs) extracted from healthy women and differentiated into mature adipocytes (hMAD\# and MAs); (C) MECs were cultured for $72 \mathrm{~h}$ with conditioned media (CM) obtained from hASCs (CM[hASC]) or MAs [CM(MA)]. Results are expressed as Percentage of MEC growth \pm SEM at $72 \mathrm{~h}$ of co-culture $(n=3$ for hMAD cells, $n=16$ for hASCs from healthy women, $n=3$ for $\left.\mathrm{CM} ;{ }^{*} p<0.05,{ }^{* *} p<0.01,{ }^{* * *} p<0.001\right)$. (B) Evaluation of apoptosis in myoepithelial cells (MECs). MECs were co-cultured or not with non-differentiated (hMAD) or differentiated hMAD (hMAD\#) for $72 \mathrm{~h}$ and stained with Annexin V-FITC and PI. [FITC-/PI-] reflected living cells; fluorescence [FITC+/PI-] and [FITC+/PI+] represented apoptotic cells. The percentage of cells is represented as the mean $\pm \mathrm{SEM},{ }^{*} p \leq 0.05$ compared to the control. Experiments were repeated in triplicate. Ctl, Control.

mature adipocytes $(R Q=52.6, p=0.001)$ (Figure $4 \mathrm{~A})$. The expression was even $\mathrm{x} 66$ in the presence of the adipocytes from obese women vs. MECs. In parallel, the expression of AdipoR1 and AdipoR2, two adiponectin receptors, were only decreased in the MECs co-cultured with mature adipocytes. Adiponectin was not detected in our experiments. Aromatase was also stimulated by mature adipocytes $(R Q=2.3, p=0.07$ and $R Q=3$, $p=0.02$ for MECs co-cultured with hASCs and MAs, respectively). Interestingly, the expression of the studied inflammatory genes, IL6, COX2, and TNF, was stimulated in the MECs in the presence of adipose precursors or mature adipocytes.

Thus, adipose cells, naturally present in the tumor microenvironment, could significantly alter the gene profile of MECs by modifying the expression of the genes involved in the maintenance of the extracellular matrix. Leptin and inflammation genes also appeared to be largely impacted.

\section{MiR-122-5p and MiR-132-3p Could Be Targets of the Adipose Microenvironment, Leading to the Loss of the Tumor Suppressor Status of the MECs}

miRNAs (or microRNAs or miRs) are small non-coding RNAs which regulate gene expression at the post-transcriptional level by inhibiting the stability or the transcriptional efficiency of target genes. Through their action of regulating the genome, miRNAs are key players in many physiopathological 

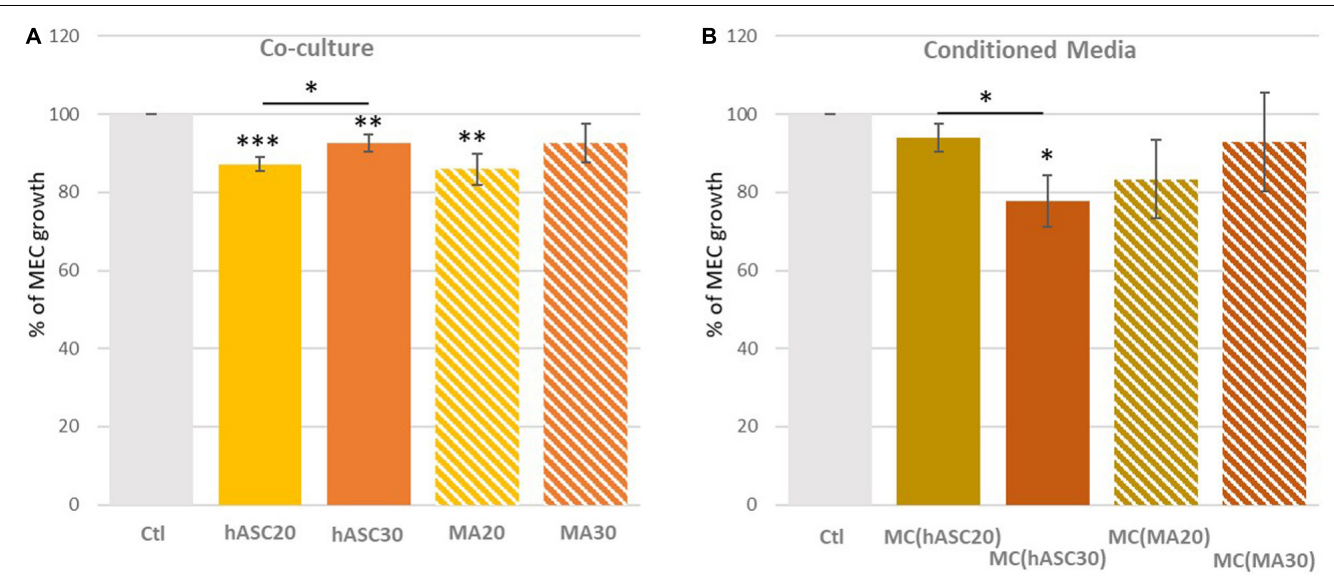

FIGURE 2 | Percentage of myoepithelial cell (MEC) viability when co-cultured with adipose cells from women of different BMI (A) or with their adipose secretome (B) (A) MECs were co-cultured for $72 \mathrm{~h}$ with human adipose stem cells (hASCs) extracted from women of normal weight (hASC20) and obese women (hASC30) and differentiated into mature adipocytes (MA20 and MA30); (B) MECs were cultured for $72 \mathrm{~h}$ with conditioned media (CM) obtained from hASCs (CM[hASC20] and $\mathrm{CM}$ [hASC30]) or MAs (CM[MA20] and CM[MA30). Results are expressed as Percentage of MEC growth \pm SEM ( $n=8$ for hASCs and MAs, $n=3$ for CM; ${ }^{*} p<0.05$, $\left.{ }^{* *} p<0.01,{ }^{* * *} p<0.001\right)$.

mechanisms, particularly cancers (He and Hannon, 2004; Yuan et al., 2019). To identify if miRNAs are involved in the modification of MEC features, we performed miRNA expression profiling analyses on the MECs co-cultured either with hASCs or MAs. Then, we looked at the influence of the BMI of the source cells.

We evaluated the expression of one of the onco-miRs which can repress tumor suppressor genes (miR-122-5p) and one of the tumor suppressor miRs which can repress oncogenes (miR-132). The onco-miR-122-5p appeared to be significantly up-regulated in MECs co-cultured with MAs compared to MECs co-cultured with hASCs $(R Q=2.403, p<0.05)$ but no significant data were obtained when we looked at the BMI of the cells (Table 1). The target genes of this oncomiR were predicted by bioinformatics software (mirPath v.3 from DIANA TOOLS) which suggested, as potential bindings, a large number of genes involved in extracellular matrix maintenance, such as collagenases, integrins, laminins (ITGB1, ITGB8, LAMB1, LAMA5, COL27A1, AGRN, LAMC3, COL4A2, COL5A1, COL4A3, CD44). On the contrary, the expression of the tumor suppressor miR-132-3p seemed to decrease in the MECs co-cultured with MAs vs. MECs co-cultured with hASCs $(R Q=0.66, p=0.132)$. A strong trend has been observed when growing with hASC30 $(R Q=0.479, p=0.064)$. The target genes of this miR are, among others, involved in the TGF $\beta$ signaling pathway (SMAD2, THBS1, ACVR2B, E2F5, SMURF1, RBL1, SMAD5, SP1, PPP2CB, MAPK1, PPP2R1B).

\section{Adipose Cell Metabolome Analysis Confirmed the Specific Profiles of Each Cell Type and Their Possible Involvement in Carcinogenesis}

In order to identify the molecules responsible for the effect of MEC functionality, the analysis of the culture media of
hASCs and of MAs differentiated from hASCs, taken from both women of normal weight and obese women, was carried out by untargeted metabolomics.

Under our conditions, 55 metabolite features from the C18(+) and 90 from the HILIC(-) analysis matched the accurate mass and retention time of the metabolites included in our chemical database, thus yielding 145 annotated metabolites in total. Differences between hASCs and MAs were investigated further using both unsupervised PCA and supervised PLSDA analysis (Figure 5). As shown in Figure 5, PLS-DA showed a good segregation of groups, suggesting significant differences in the metabolic composition between hASCs and MAs. Permutation tests (100 times) were conducted to assess the robustness of the PLS-DA model when using a small sample size. Complementary to these multivariate analyses, an univariate analysis was applied using pairwise comparisons (hASCs vs. MAs) of individual metabolites (Wilcoxon $p$-values with Benjamini-Hochberg correction). Under these conditions, up to 31 annotated metabolites proved significant and were subjected to additional MS/MS experiments for identity confirmation (Table 2). Those metabolites belonged to several metabolic pathways, such as the BCAA metabolism (branched-chain amino acid), the antioxidant response, the nucleotide metabolism and the energy metabolism pathways. It appeared that hASCs and MAs presented different metabolic patterns characterized by an increase in the content of AA (glutamate, serine) and of free fatty acids for hASCs and, for MAs, by an increase in the content of BCAA intermediates, ketone bodies and carbohydrate metabolites. The 31 metabolites were then analyzed by the MetExplore tool to identify discriminately perturbed metabolic pathways. The following metabolic pathways proved significantly impacted: the pyrimidine catabolism pathway; the valine, leucine, and isoleucine pathways; the alanine and aspartate pathways. 


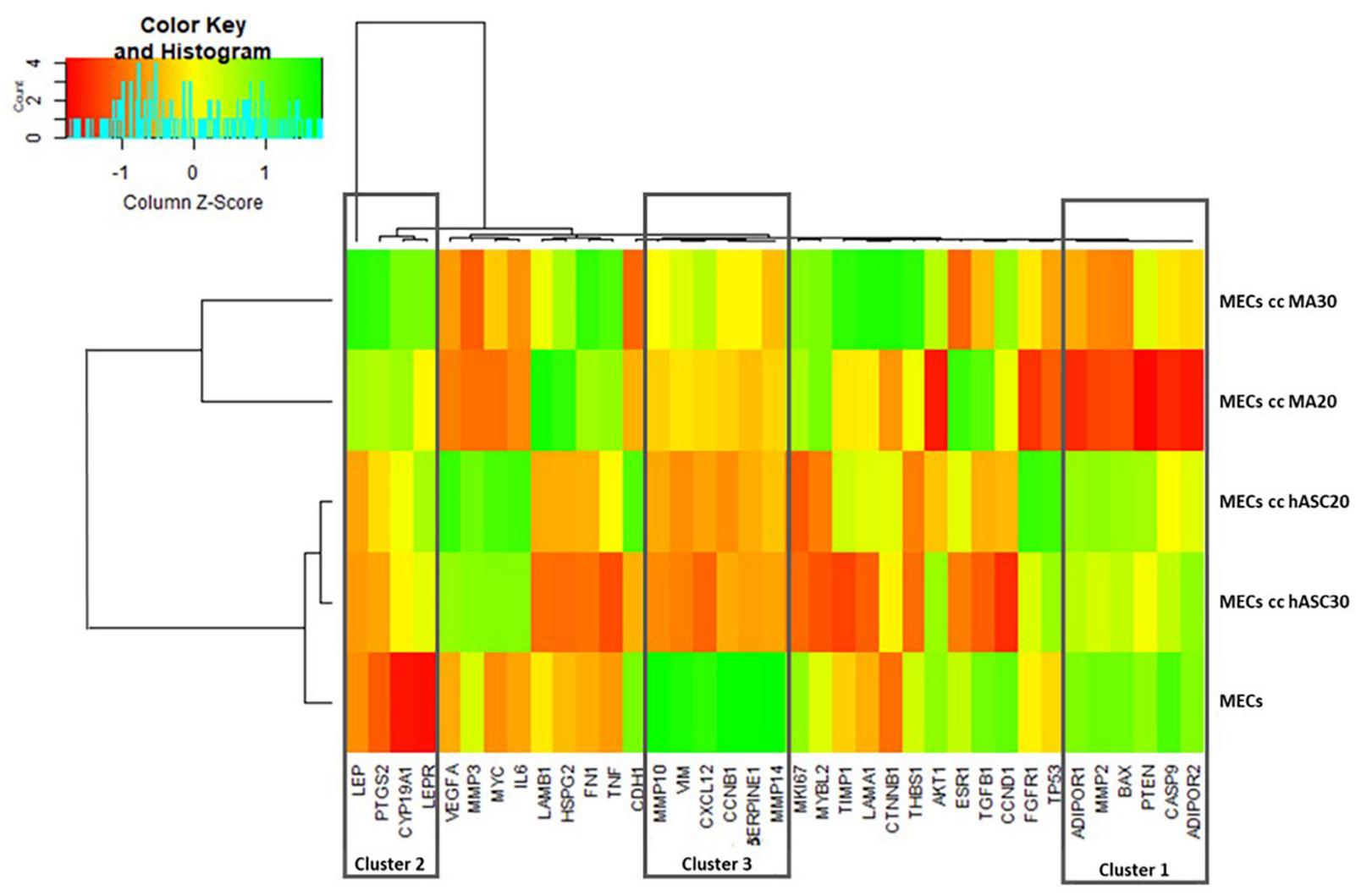

FIGURE 3 | Heatmap with hierarchical clustering (red for under-expressed, yellow for unchanged expression, and green for over-expressed genes).

\section{DISCUSSION}

Myoepithelial cells (MECs) are considered as tumor suppressor by regulating the functions of normal cells and by inhibiting the invasion of breast cancer cells. Studies have shown that an alteration to the functions of MECs leads to an increase in the facility of cells to migrate. So a modification to the functionality of MECs could promote carcinogenesis instead of suppressing it. Authors have hypothesized that MECs lose their tumorsuppressive features thus participating in the invasive cancer progression through the involvement of the microenvironment and the destruction of the basement membrane (Gudjonsson et al., 2002; Allinen et al., 2004; Payne et al., 2009; Lo et al., 2017). In this study, we have tried to elucidate the role of the adipose microenvironment in the modification of MEC features and wanted to evaluate if adipose cells and their secretome could modify the behavior of MECs and, consequently, be involved in the progression of cancer.

Using a co-culture model with myoepithelial cells and human adipose cells (hASCs and MAs) from women of normal weight and from obese women, we have shown that hASCs can reduce the viability of MECs, regardless of initial BMI. However, only MA20s would be able to significantly reduce the proliferation of MECs. To our knowledge, this is the first experimental evidence evaluating the impact of adipose cells on MECs in the context of breast cancer. The roles played by each cell type can probably explain the observed differences. For example, hASCs retain their ability to proliferate contrary to MAs, permitting the phenomenon of hyperplasia (Ailhaud, 1998). The different secretory activity between these two cell types is also described. hASCs are able, such as MAs, to produce some molecules, such as IGF-1, IGF-BP1,2,3, whereas the secretion of leptin is exclusively secreted by MAs (Szatkowski et al., 2013).

Our study of gene expression modifications in co-cultured MECs, in the presence of adipose cells, showed that the genes coding for the maintenance of the extracellular matrix could play a key role in the observed modifications, as did leptin and certain inflammatory genes.

One of the hallmarks of cancer is the loss of a normal tissue polarity. Our data revealed a decreased expression of Serpine-1 and an increased expression of fibronectin. During the invasive process, a lack or a dysfunction of MECs is observed. Serpine-1 (=PAI1) has been associated with breast cancer clinical outcome and is involved in the interactions between the tumor and its microenvironment, particularly in breast cancer (Vénat-Bouvet et al., 2012; Ferroni et al., 2014). In addition, Serpine-1 is known to play an important role in cell adhesion, migration and invasion ( $\mathrm{Li}$ et al., 2018). On the contrary, Fibronectin (FN), a key component of the tumor ECM, seems to facilitate tumor formation, proliferation and angiogenesis. Its expression in breast tissue 


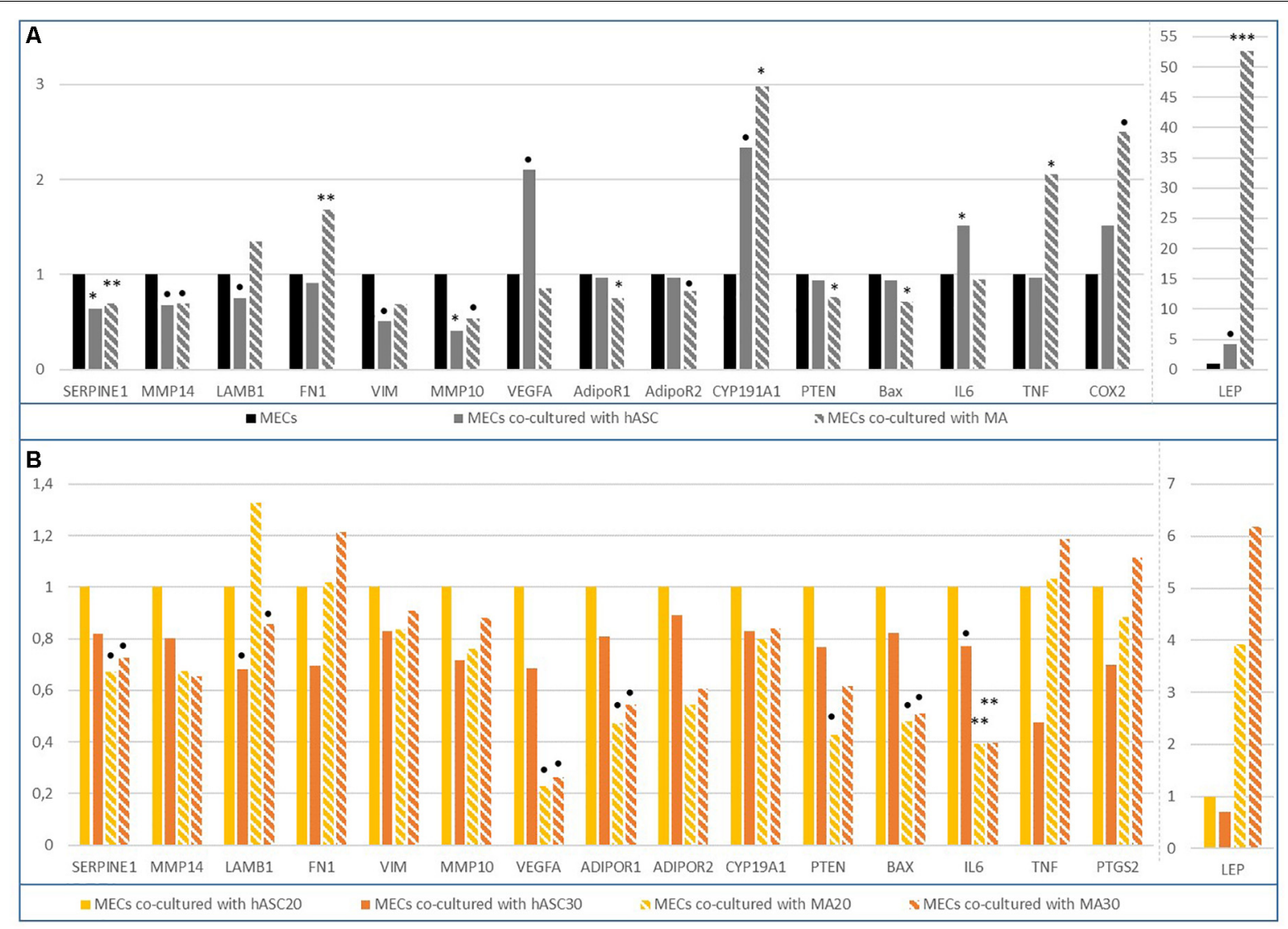

FIGURE 4 | Differential gene expression in MECs co-cultured with adipose cells. (A) Differential gene expression in MECs co-cultured with human adipose stem cells (hASCs) or mature adipocytes (MAs); (B) Differential gene expression in MECs co-cultured either with hASC30 or MA20 or MA30 vs. MECs co-cultured with hASC20. ${ }^{*} p<0.05,{ }^{* *} p<0.01,{ }^{* * *} p<0.001, p<0.2$.

TABLE 1 | Up- or down-regulated miRNAs in co-cultured MECs.

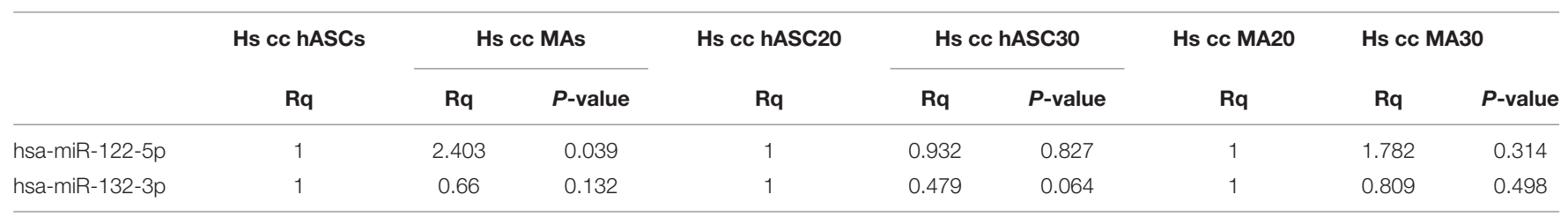

was positively correlated with an invasive and metastatic phenotype and negatively associated with survival and clinical outcome in breast cancer patients (Chen et al., 2019). Thus these two genes could constitute privileged targets for the action of adipose cells leading to the loss of MEC function. Members of the matrix metalloproteinase (MMP) family also constitute poor prognosis markers. In our study, a significant decrease in the expression of MMP14/10 was observed but, the variation was not notable for any other of the MMPs studied. Proteases are preferentially overexpressed during carcinogenesis to permit the destruction of the basement membrane and the invasion of cancer cells (Radisky and Radisky, 2015). In fact, MMPs are often produced not by epithelial cancer or myoepithelial cells but by environmental cells such as fibroblasts, macrophages (Chantrain and DeClerck, 2002) which could explain our results.

One interesting result is the impressive increase in leptin expression, particularly in the MECs co-cultured with MAs and MA30. Leptin is an adipokine whose synthesis is positively correlated with the BMI and is mainly produced by adipose cells but also by epithelial tumor cells and cells in the microenvironment, such as fibroblasts. A lot of studies have confirmed the pro-carcinogenic role of leptin through the stimulation of proliferation, migration and invasion of tumor cells (Jarde et al., 2008; Caldefie-Chézet et al., 2013; Andò et al., 2019). Thus, the adipose microenvironment could be said to play a key role in modulating the secretion of this adipokine by the 


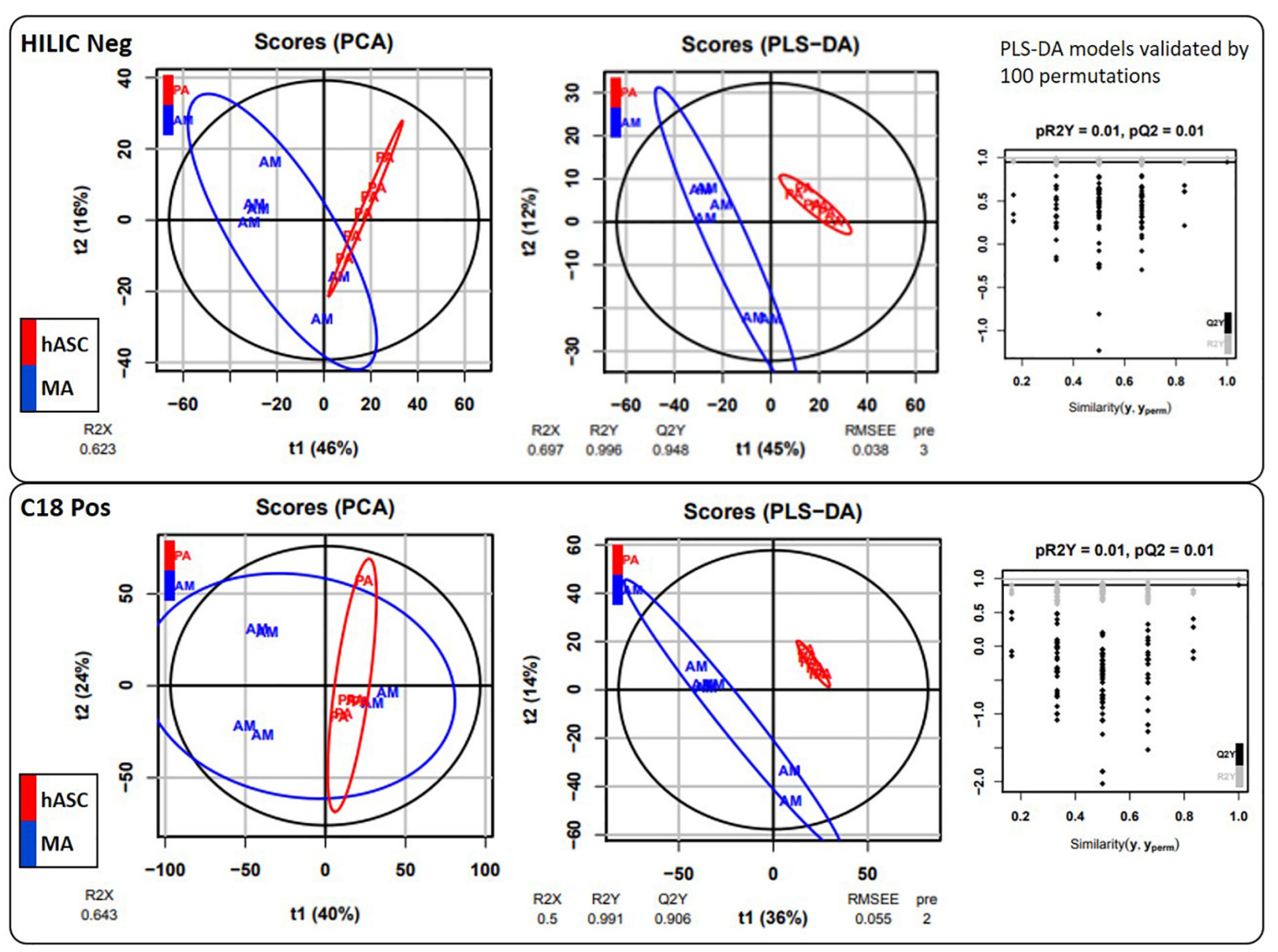

FIGURE 5 | Multivariate statistical analyses. Chromatographic peak areas, contained in the two filtered and processed XCMS data matrices HILIC(-) and C18(+) (top and bottom panel, respectively), were studied using multivariate analysis (PCA, PLS-DA).

MECs, which can, in turn, stimulate the proliferation of cancer cells.

Inflammation seemed to be a major biological pathway to consider. Indeed, the higher gene expression of TNF, IL-6 and COX2 in our model suggested the impact of the adipose cells. Obesity is described as associated with a chronic low-grade inflammation status characterized by the secretion of pro-inflammatory mediators (Iyengar et al., 2013). Adipose tissue produces pro-inflammatory cytokines (TNF $\alpha$, TGF $\beta$, IFN $\gamma$, IL1, IL6, IL10, IL8), chemokines (MCP1) and other biomolecules, such as PAI-1. In obese individuals, the production of these factors is altered with a balance toward proinflammatory factors leading to the development of low-grade systemic inflammation (Trayhurn, 2005). Low-grade chronic inflammation promotes cell proliferation through the influx of immune cells, the production of pro-inflammatory mediators and growth factors, tissue remodeling and angiogenesis (Iyengar et al., 2016).

To explain the changes in the characteristics of MECs, the other hypothesis considered here is the involvement of miRNAs. Indeed, miRNAs can be considered novel regulators in the distinctive features of human cancer (Ruan et al., 2009). A lot of studies have highlighted the involvement of miRNAs in the physiopathology of many diseases, including cancers (He and Hannon, 2004). miRNAs could be considered as tumor suppressor miRs (by repressing oncogenes) or as onco-miRs (by repressing tumor suppressor genes) according to their target gene and the tissue in which they are expressed (Zografos et al., 2019). Like any epigenetic mechanism, miRNA expression is dependent on environmental factors. In the present case, we hypothesized that the adipose microenvironment might be able to modify the expression of miRNA. In this regard, we focused on one onco-miRNA, miR-122-5p, which appeared upregulated in the MECs co-cultured with MAs. The use of dedicated bioinformatics software has enabled us to identify potential target genes involved in extracellular matrix maintenance, such as collagenases, integrins, laminins. Thus, the deregulation of this miRNA could be implicated in the significant degradation of the extracellular matrix which would no longer be regulated by the MECs. miR-122 is described as being associated with invasion and epithelial-mesenchymal transition. This miRNA seemed to be more expressed in 
TABLE 2 | Annotated and significant metabolites.

\begin{tabular}{|c|c|c|c|c|c|c|}
\hline $\begin{array}{l}\text { KEGG pathway } \\
\text { families }\end{array}$ & $\begin{array}{l}\text { KEGG } \\
\text { pathways }\end{array}$ & Subpathways & Name & $\begin{array}{c}\text { Ratio } \\
\text { hASC/MA }\end{array}$ & $\begin{array}{c}p- \\
\text { value } \\
(\mathrm{BH})\end{array}$ & $\begin{array}{c}\text { Identification } \\
\text { status }\end{array}$ \\
\hline \multirow[t]{10}{*}{ Amino acid metabolism } & \multirow[t]{2}{*}{$\begin{array}{l}\text { Alanine and } \\
\text { aspartate }\end{array}$} & Aspartate & Asparagine & 0.29 & 0.048 & $a, c, e$ \\
\hline & & Glutamate & Glutamic acid & 13.18 & 0.019 & $a, b, d$ \\
\hline & \multirow[t]{2}{*}{$\begin{array}{l}\text { Glycine and } \\
\text { serine }\end{array}$} & \multirow[t]{2}{*}{ Serine } & Serine & 1.94 & 0.019 & $a, b, d$ \\
\hline & & & $\mathrm{N}$-Acetylserine & 0.62 & 0.019 & $a, b, d$ \\
\hline & Methionine & Methionine & Methionine & 0.76 & 0.042 & $a, b, d$ \\
\hline & \multirow[t]{5}{*}{$\begin{array}{l}\text { Valine, leucine, } \\
\text { and isoleucine } \\
\text { degradation }\end{array}$} & Leucine & Methyloxopentanoic acid & 0.36 & 0.019 & $a, b, d$ \\
\hline & & \multirow[t]{4}{*}{ Others } & Hydroxy 3-methylbutyric acid & 0.58 & 0.019 & $a, b, d$ \\
\hline & & & Hydroxy-2-methyl butanoic acid (HMBA) & 0.53 & 0.019 & $a, b, d$ \\
\hline & & & 3-Methyl-2-oxovaleric acid & 0.36 & 0.019 & $a, b, d$ \\
\hline & & & Hydroxy 3-methylbutyric acid & 0.58 & 0.019 & $a, b, d$ \\
\hline \multirow[t]{7}{*}{ Nucleotide metabolism } & \multirow[t]{2}{*}{$\begin{array}{l}\text { Purine } \\
\text { metabolism }\end{array}$} & $\begin{array}{l}\text { Inosine and } \\
\text { xanthine }\end{array}$ & Hypoxanthine & 2.68 & 0.019 & $a, b, d$ \\
\hline & & Allantoin & Allantoin & 1.22 & 0.029 & $a, b, d$ \\
\hline & \multirow[t]{5}{*}{$\begin{array}{l}\text { Pyrimidine } \\
\text { metabolism }\end{array}$} & \multirow[t]{2}{*}{ Uracil } & Uracil & 0.63 & 0.019 & $a, b, d$ \\
\hline & & & 3-Ureidopropionic acid & 0.29 & 0.048 & $a, b, d$ \\
\hline & & Others & Beta-Pseudouridine & 0.9 & 0.042 & $a, b, d$ \\
\hline & & \multirow[t]{2}{*}{ Thymidine } & Thymidine & 9.18 & 0.019 & $a, b, d$ \\
\hline & & & Thymine & 5.25 & 0.019 & $a, b$ \\
\hline \multirow[t]{4}{*}{$\begin{array}{l}\text { Carbohydrate } \\
\text { metabolism }\end{array}$} & \multirow[t]{2}{*}{$\begin{array}{l}\text { Ascorbate and } \\
\text { aldarate }\end{array}$} & Sucrose & Myo-Inositol & 1.19 & 0.042 & $a, b, d$ \\
\hline & & Others & Threonic acid & 0.62 & 0.019 & $a, b, d$ \\
\hline & $\begin{array}{l}\text { Pyruvate } \\
\text { metabolism }\end{array}$ & Pyruvate & Lactic acid & 0.51 & 0.019 & $a, b, d$ \\
\hline & $\begin{array}{l}\text { Butanoate } \\
\text { metabolism }\end{array}$ & 2-Oxoglutarate & Hydroxyglutaric acid & 0.8 & 0.042 & $a, b, d$ \\
\hline \multirow[t]{10}{*}{ Lipid metabolism } & $\begin{array}{l}\text { Synthesis and } \\
\text { degradation of } \\
\text { ketone bodies }\end{array}$ & Ketone bodies & Hydroxybutanoic acid & 0.18 & 0.019 & $a, b, d$ \\
\hline & \multirow[t]{9}{*}{ Fatty acids } & \multirow[t]{3}{*}{ Straight chain } & Hexanoic acid & 1.71 & 0.019 & $a, b$ \\
\hline & & & Nonanoic acid & 1.47 & 0.029 & $a, b$ \\
\hline & & & Decanoic acid & 1.39 & 0.029 & $a, b, d$ \\
\hline & & Monounsaturated & Octadecenoic acid & 3.26 & 0.019 & $a, b$ \\
\hline & & \multirow[t]{2}{*}{ Polyunsaturated } & Eicosatrienoic acid & 10.35 & 0.019 & $a, b$ \\
\hline & & & Eicosapentaenoic acid & 2.51 & 0.019 & $a, b, d$ \\
\hline & & \multirow[t]{3}{*}{ Hydroxy } & Hydroxypentanoic acid & 0.58 & 0.019 & $a, b, d$ \\
\hline & & & Hydroxyhexanoic acid & 0.41 & 0.019 & $a, b, d$ \\
\hline & & & Hydroxyhexadecanoic acid & 2.29 & 0.019 & $a, b, d$ \\
\hline
\end{tabular}

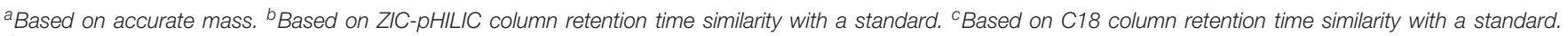
${ }^{d}$ Based on $\mathrm{MS}^{2}$ spectrum (ESI neg) similarity with a standard. ${ }^{e}$ Based on $\mathrm{MS}^{2}$ spectrum (ESI pos) similarity with a standard.

distant metastases than in primary tumors (Uen et al., 2018) and may be a marker predicting clinical outcome of locally advanced breast cancer (Wu et al., 2012). However, some authors described miRNA as having the dual effect of tumor suppressor and oncomiR. It could promote cell survival in acquired radioresistant breast cancer (Perez-Añorve et al., 2019). On the contrary, miR-132-3p, described as a tumor suppressor miRNA, appeared down-regulated in the MECs co-cultured with MAs. Genes involved in the TGF $\beta$ signaling pathway appeared to be predicted targets of this miR, suggesting that the adipose environment could be responsible for a decrease in the MEC protective effect, favoring tumor progression. miR132 is known as a tumor suppressor miR and some authors have associated it with reduced proliferation through its action on different targets (LAPTM4B, FOXA1) (Wang et al., 2018; Li et al., 2019). 
The metabolic distinction between hASCs and MAs, particularly regarding the lipid metabolism, could also explain the observed differences in the viability assays. That's why the identification of a cocktail of potentially bioactive molecules responsible for the described effects on the MECs has been one of our objectives. Analysis of the medium metabolome showed a strong difference between hASCs and MAs. The hASC medium was richer in glutamate, thymidine and free fatty acids and, conversely, presented a decrease in some BCAA metabolites, ketone bodies and carbohydrate metabolites. These observations suggested that, contrary to MAs, hASCs were in abundance and proliferated, resulting in the decrease of numerous metabolites implied in the synthesis of nucleotides. As well, cellular energy production was also found to be perturbed with the levels of some ketone bodies and carbohydrate metabolites being significantly impacted. In parallel, the glutamate, thymidine and free fatty acids are released in the medium and it is recognized that it might be useful to neoplastic cells as they are essential metabolites for tumor growth (O'Connell, 2013; Günther, 2015; Röhrig and Schulze, 2016). These data confirmed the roles of these two cell types described in the literature and may explain the differences observed in our co-culture assays.

Conversely, the metabolic pattern of MAs confirmed the slowdown of adipocyte proliferation but, concurrently, a change in metabolic function. The huge decrease of secreted free fatty acids highlighted the storage function of adipocytes. At the same time, it is interesting to note that, among the fatty acids identified, the two precursors of eicosanoids (dihomo gamma linoleic acid and eicosapentaenoic acid) were decreased in the medium of MAs. This observation in link with the decrease of glutamate suggested that an inflammation and antioxidant response may appear in MAs (Basu et al., 2015; Stepien et al., 2016), which we confirmed when studying gene expression in MECs (increased $I L-6, T N F$ and COX2 expression). In parallel, the increase in some BCAA metabolites in the environment of MAs (Leucine, isoleucine, and valine which are key regulators of protein synthesis) is in link with the metabolic switch of adipocytes and may be reinforced in an obese situation in agreement with previous data (Wang et al., 2017). The impact of BCAA on MECs has not yet been studied to our knowledge. But it is accepted that an increase in the BCAA metabolic pathway reinforces the ability of cancer cell proliferation as these metabolites are well known to be regulators of many cell signaling pathways, such as phosphorylated mTOR, S6K1, and IRS1, implied in insulin resistance and cell proliferation (O'Connell, 2013; Kogut et al., 2015; Hattori et al., 2017). Our preliminary data suggest that complementary assays should be investigated to evaluate the impact of the identified metabolites on MECs.

\section{CONCLUSION}

In summary, we studied the molecular modifications of MECs surrounded by adipose cells in order to understand whether these cells and their secretome were able to disrupt the functionality of MECs and thus lead to a possible invasion of cancer cells. We have demonstrated that adipose cells, key players in the mammary tumor microenvironment, are able to act on MECs and that they could, in this way, contribute to the loss of tumor suppressor status of these cells.

\section{DATA AVAILABILITY STATEMENT}

The datasets generated for this study are publicly available. This data can be found here: MassIVE MSV000086515.

\section{ETHICS STATEMENT}

Written informed consent was obtained from the individual(s) for the publication of any potentially identifiable images or data included in this article.

\section{AUTHOR CONTRIBUTIONS}

LD conducted the experiments, analyzed and interpreted the data, and wrote the manuscript. JC and AR developed the analysis methods and analyzed the data. FC and FF conducted the metabolomic experiments, interpreted the data, and wrote the manuscript. CAD and $\mathrm{MV}$ conducted the experiments and wrote the manuscript. $\mathrm{CHD}$ and $\mathrm{CA}$ participated in the collection of cells and interpreted the data. FCC conceptualized the study, analyzed and interpreted the data, and wrote the manuscript. All authors reviewed and approved the final version of the manuscript.

\section{FUNDING}

The study was supported by the Fondation ARC for cancer research (PJA 20151203132).

\section{ACKNOWLEDGMENTS}

We thank Ali Mojallal for his participation in the collection of hASCs. We wish to acknowledge Céline Boby from the Platform for Exploring Metabolism-transcriptomics component (INRAE Theix, France) for her help in gene expression analysis.

\section{SUPPLEMENTARY MATERIAL}

The Supplementary Material for this article can be found online at: https://www.frontiersin.org/articles/10.3389/fcell.2020. 571948/full\#supplementary-material 


\section{REFERENCES}

Adriance, M. C., Inman, J. L., Petersen, O. W., and Bissell, M. J. (2005). Myoepithelial cells: good fences make good neighbors. Breast Cancer Res. 7, 190-197. doi: 10.1186/bcr1286

Ailhaud, G. (1998). L'adipocyte, cellule sécrétrice et endocrine. Adipocyte 14, 858-864. doi: 10.4267/10608/1157

Allen, M. D., Marshall, J. F., and Jones, J. L. (2014). $\alpha v \beta 6$ Expression in myoepithelial cells: a novel marker for predicting DCIS progression with therapeutic potential. Cancer Res. 74, 5942-5947. doi: 10.1158/0008-5472. CAN-14-1841

Allinen, M., Beroukhim, R., Cai, L., Brennan, C., Lahti-Domenici, J., Huang, H., et al. (2004). Molecular characterization of the tumor microenvironment in breast cancer. Cancer Cell 6, 17-32. doi: 10.1016/j.ccr.2004.06.010

Andò, S., Gelsomino, L., Panza, S., Giordano, C., Bonofiglio, D., Barone, I., et al. (2019). Obesity, Leptin and Breast Cancer: epidemiological Evidence and Proposed Mechanisms. Cancers 11:62. doi: 10.3390/cancers11010062

Basu, S., Combe, K., Kwiatkowski, F., Caldefie-Chézet, F., Penault-Llorca, F., Bignon, Y.-J., et al. (2015). Cellular expression of cyclooxygenase, aromatase, adipokines, inflammation and cell proliferation markers in breast cancer specimen. PLoS One 10:e0138443. doi: 10.1371/journal.pone.013 8443

Boudah, S., Olivier, M.-F., Aros-Calt, S., Oliveira, L., Fenaille, F., Tabet, J.-C., et al. (2014). Annotation of the human serum metabolome by coupling three liquid chromatography methods to high-resolution mass spectrometry. J. Chromatogr. B Analyt. Technol. Biomed. Life Sci. 966, 34-47. doi: 10.1016/j.jchromb.2014.04. 025

Bougaret, L., Delort, L., Billard, H., Le Huede, C., Boby, C., De la Foye, A., et al. (2018). Adipocyte/breast cancer cell crosstalk in obesity interferes with the antiproliferative efficacy of tamoxifen. PLoS One 13:e0191571. doi: 10.1371/journal. pone.0191571

Bougaret, L., Delort, L., Billard, H., Lequeux, C., Goncalves-Mendes, N., Mojallal, A., et al. (2017). Supernatants of adipocytes from obese versus normal weight women and breast cancer cells: in vitro impact on angiogenesis. J. Cell. Physiol. 232, 1808-1816. doi: 10.1002/jcp.25701

Caldefie-Chézet, F., Dubois, V., Delort, L., Rossary, A., and Vasson, M.-P. (2013). Leptin: involvement in the pathophysiology of breast cancer. Ann. Endocrinol. 74, 90-101. doi: 10.1016/j.ando.2013.03.005

Chamberlin, T., D’Amato, J. V., and Arendt, L. M. (2017). Obesity reversibly depletes the basal cell population and enhances mammary epithelial cell estrogen receptor alpha expression and progenitor activity. Breast Cancer Res. 19:128. doi: 10.1186/s13058-017-0921-7

Chantrain, C., and DeClerck, Y. A. (2002). Les métalloprotéases matricielles et leurs inhibiteurs synthétiques dans la progression tumorale. Med. Sci. 18, 565-575. doi: 10.1051/medsci/2002185565

Chen, Y., Chen, L., Hong, D., Chen, Z., Zhang, J., Fu, L., et al. (2019). Baicalein inhibits fibronectin-induced epithelial-mesenchymal transition by decreasing activation and upregulation of calpain-2. Cell Death Dis. 10, 1-15. doi: 10.1038/ s41419-019-1572-7

Cottret, L., Frainay, C., Chazalviel, M., Cabanettes, F., Gloaguen, Y., Camenen, E., et al. (2018). MetExplore: collaborative edition and exploration of metabolic networks. Nucleic Acids Res. 46, W495-W502. doi: 10.1093/nar/gky301

Delort, L., Bougaret, L., Cholet, J., Vermerie, M., Billard, H., Decombat, C., et al. (2019). Hormonal therapy resistance and breast cancer: involvement of adipocytes and leptin. Nutrients 11:2839. doi: 10.3390/nu11122839

Dignam, J. J., Wieand, K., Johnson, K. A., Fisher, B., Xu, L., and Mamounas, E. P. (2003). Obesity, tamoxifen use, and outcomes in women with estrogen receptor-positive early-stage breast cancer. J. Natl. Cancer Inst. 95, 1467-1476. doi: 10.1093/jnci/djg060

Ferlay, J., Colombet, M., Soerjomataram, I., Mathers, C., Parkin, D. M., Piñeros, M., et al. (2019). Estimating the global cancer incidence and mortality in 2018: GLOBOCAN sources and methods. Int. J. Cancer 144, 1941-1953. doi: 10.1002/ ijc. 31937

Ferroni, P., Roselli, M., Portarena, I., Formica, V., Riondino, S., La Farina, F., et al. (2014). Plasma plasminogen activator inhibitor-1 (PAI-1) levels in breast cancer - relationship with clinical outcome. Anticancer Res. 34, 1153-1161.

Giacomoni, F., Le Corguille, G., Monsoor, M., Landi, M., Pericard, P., Petera, M., et al. (2015). Workflow4Metabolomics: a collaborative research infrastructure for computational metabolomics. Bioinformatics 31, 1493-1495. doi: 10.1093/ bioinformatics/btu813

Gudjonsson, T., Rønnov-Jessen, L., Villadsen, R., Rank, F., Bissell, M. J., and Petersen, O. W. (2002). Normal and tumor-derived myoepithelial cells differ in their ability to interact with luminal breast epithelial cells for polarity and basement membrane deposition. J. Cell Sci. 115, 39-50.

Günther, U. L. (2015). Metabolomics Biomarkers for Breast Cancer. Pathobiology 82, 153-165. doi: 10.1159/000430844

Hattori, A., Tsunoda, M., Konuma, T., Kobayashi, M., Nagy, T., Glushka, J., et al. (2017). Cancer progression by reprogrammed BCAA metabolism in myeloid leukaemia. Nature 545, 500-504. doi: 10.1038/nature22314

He, L., and Hannon, G. J. (2004). MicroRNAs: small RNAs with a big role in gene regulation. Nat. Rev. Genet. 5, 522-531. doi: 10.1038/nrg1379

Iyengar, N. M., Gucalp, A., Dannenberg, A. J., and Hudis, C. A. (2016). Obesity and cancer mechanisms: tumor microenvironment and Inflammation. J. Clin. Oncol. 34, 4270-4276. doi: 10.1200/JCO.2016.67.4283

Iyengar, N. M., Hudis, C. A., and Dannenberg, A. J. (2013). Obesity and inflammation: new insights into breast cancer development and progression. Am. Soc. Clin. Oncol. Educ. Book 33, 46-51. doi: 10.1200/EdBook_AM.2013. 33.46

Jarde, T., Caldefie-Chezet, F., Damez, M., Mishellany, F., Penault-Llorca, F., Guillot, J., et al. (2008). Leptin and leptin receptor involvement in cancer development: a study on human primary breast carcinoma. Oncol. Rep. 19, 905-911.

Jones, J. L., Shaw, J. A., Pringle, J. H., and Walker, R. A. (2003). Primary breast myoepithelial cells exert an invasion-suppressor effect on breast cancer cells via paracrine down-regulation of MMP expression in fibroblasts and tumour cells. J. Pathol. 201, 562-572. doi: 10.1002/path.1483

Kogut, M. H., Genovese, K. J., He, H., and Arsenault, R. J. (2015). AMPK and mTOR: sensors and regulators of immunometabolic changes during Salmonella infection in the chicken. Poult. Sci 95, 345-353. doi: 10.3382/ps/ pev349

Lequeux, C., Auxenfans, C., Mojallal, A., Sergent, M., and Damour, O. (2009). Optimization of a culture medium for the differentiation of preadipocytes into adipocytes in a monolayer. Biomed. Mater. Eng. 19, 283-291.

Li, S., Wei, X., He, J., Tian, X., Yuan, S., and Sun, L. (2018). Plasminogen activator inhibitor-1 in cancer research. Biomed. Pharmacother. 105, 83-94. doi: 10.1016/ j.biopha.2018.05.119

Li, S., Xu, J.-J., and Zhang, Q.-Y. (2019). MicroRNA-132-3p inhibits tumor malignant progression by regulating lysosomal-associated protein transmembrane 4 beta in breast cancer. Cancer Sci. 110, 3098-3109. doi: $10.1111 /$ cas. 14164

Lo, P.-K., Zhang, Y., Yao, Y., Wolfson, B., Yu, J., Han, S.-Y., et al. (2017). Tumorassociated myoepithelial cells promote the invasive progression of ductal carcinoma in situ through activation of TGF $\beta$ signaling. J. Biol. Chem. 292, 11466-11484. doi: 10.1074/jbc.M117.775080

Mojallal, A., Auxenfans, C., Lequeux, C., Braye, F., and Damour, O. (2008). Influence of negative pressure when harvesting adipose tissue on cell yield of the stromal-vascular fraction. Biomed. Mater. Eng. 18, 193-197.

O'Connell, T. M. (2013). The complex role of branched chain amino acids in diabetes and cancer. Metabolites 3, 931-945. doi: 10.3390/metabo3040931

Payne, S., Allen, M., Dreger, S., Marshall, J., Hodiavala-Dilke, K., Hart, I., et al. (2009). Myoepithelial Cells in DCIS Exhibit an altered phenotype and promote angiogenesis. Cancer Res. 69:2155. doi: 10.1158/0008-5472.SABCS-092155

Perez-Añorve, I. X., Rosa, C. H. G.-D., Soto-Reyes, E., Beltran-Anaya, F. O., Moral-Hernandez, O. D., Salgado-Albarran, M., et al. (2019). New insights into radioresistance in breast cancer identify a dual function of miR-122 as a tumor suppressor and oncomiR. Mol. Oncol. 13, 1249-1267. doi: 10.1002/1878-0261. 12483

Picon-Ruiz, M., Morata-Tarifa, C., Valle-Goffin, J. J., Friedman, E. R., and Slingerland, J. M. (2017). Obesity and adverse breast cancer risk and outcome: mechanistic insights and strategies for intervention. CA Cancer J. Clin. 67, 378-397. doi: 10.3322/caac.21405

Place, A. E., Jin Huh, S., and Polyak, K. (2011). The microenvironment in breast cancer progression: biology and implications for treatment. Breast Cancer Res. 13:227. doi: $10.1186 /$ bcr2912 
Polyak, K., and Hu, M. (2005). Do myoepithelial cells hold the key for breast tumor progression? J. Mamm. Gland Biol. Neopl. 10, 231-247.

Quail, D. F., and Dannenberg, A. J. (2019). The obese adipose tissue microenvironment in cancer development and progression. Nat. Rev. Endocrinol. 15, 139-154. doi: 10.1038/s41574-018-0126-x

Radisky, E. S., and Radisky, D. C. (2015). Matrix metalloproteinases as breast cancer drivers and therapeutic targets. Front. Biosci. 20:1144-1163. doi: 10. $2741 / 4364$

Röhrig, F., and Schulze, A. (2016). The multifaceted roles of fatty acid synthesis in cancer. Nat. Rev. Cancer 16, 732-749. doi: 10.1038/nrc.2016.89

Ruan, K., Fang, X., and Ouyang, G. (2009). MicroRNAs: novel regulators in the hallmarks of human cancer. Cancer Lett. 285, 116-126. doi: 10.1016/j.canlet. 2009.04.031

Sirka, O. K., Shamir, E. R., and Ewald, A. J. (2018). Myoepithelial cells are a dynamic barrier to epithelial dissemination. J. Cell Biol. 217, 3368-3381. doi: $10.1083 /$ jcb.201802144

Stepien, M., Duarte-Salles, T., Fedirko, V., Floegel, A., Barupal, D. K., Rinaldi, S., et al. (2016). Alteration of amino acid and biogenic amine metabolism in hepatobiliary cancers: findings from a prospective cohort study. Int. J. Cancer 138, 348-360. doi: 10.1002/ijc.29718

Sumner, L. W., Amberg, A., Barrett, D., Beale, M. H., Beger, R., Daykin, C. A., et al. (2007). Proposed minimum reporting standards for chemical analysis Chemical Analysis Working Group (CAWG) Metabolomics Standards Initiative (MSI). Metabolomics 3, 211-221. doi: 10.1007/s11306-007-0082-2

Szatkowski, C., Vallet, J., Dormishian, M., Messaddeq, N., Valet, P., Boulberdaa, M., et al. (2013). Prokineticin receptor 1 as a novel suppressor of preadipocyte proliferation and differentiation to control obesity. PLoS One 8:e81175. doi: 10.1371/journal.pone.0081175

Trayhurn, P. (2005). Adipose tissue in obesity-an inflammatory issue. Endocrinology 146, 1003-1005. doi: 10.1210/en.2004-1597

Uen, Y., Wang, J.-W., Wang, C., Jhang, Y., Chung, J.-Y., Tseng, T., et al. (2018). Mining of potential microRNAs with clinical correlation - regulation of syndecan-1 expression by miR-122-5p altered mobility of breast cancer cells and possible correlation with liver injury. Oncotarget 9, 28165-28175. doi: 10.18632/oncotarget.25589

Vénat-Bouvet, L., Fermeaux, V., Saidi, N., Monteil, J., Mollard, J., Aubard, Y., et al. (2012). "Utilisation de uPA-PAI-1 dans les cancers du sein sans envahissement ganglionnaire pour indiquer ou pas une chimiothérapie adjuvante, à propos de 120 cas," in Cancer du sein: surdiagnostic, surtraitement, eds B. Séradour, P. Bonnier, and J. Jacquemier (Paris: Springer), 264-265. doi: 10.1007/978-28178-0249-7_63
Vlachos, I. S., Zagganas, K., Paraskevopoulou, M. D., Georgakilas, G., Karagkouni, D., Vergoulis, T., et al. (2015). DIANA-miRPath v3.0: deciphering microRNA function with experimental support. Nucl. Acids Res. 43, W460-W466. doi: 10.1093/nar/gkv403

Walter, M., Liang, S., Ghosh, S., Hornsby, P. J., and Li, R. (2009). Interleukin 6 secreted from adipose stromal cells promotes migration and invasion of breast cancer cells. Oncogene 28, 2745-2755.

Wang, D., Ren, J., Ren, H., Fu, J.-L., and Yu, D. (2018). MicroRNA-132 suppresses cell proliferation in human breast cancer by directly targeting FOXA1. Acta Pharmacol. Sin. 39, 124-131. doi: 10.1038/aps.2017.89

Wang, Q., Holmes, M. V., Davey Smith, G., and Ala-Korpela, M. (2017). Genetic support for a causal role of insulin resistance on circulating branched-chain amino acids and inflammation. Diabetes Care 40, 1779-1786. doi: 10.2337/ dc17-1642

World Cancer Research Fund [WCRF] (2017). Diet and Cancer. London: World Cancer Research Fund.

Wu, X., Somlo, G., Yu, Y., Palomares, M. R., Li, A. X., Zhou, W., et al. (2012). De novo sequencing of circulating miRNAs identifies novel markers predicting clinical outcome of locally advanced breast cancer. J. Transl. Med. 10:42. doi: 10.1186/1479-5876-10-42

Yadav, N. V. S., Barcikowski, A., Uehana, Y., Jacobs, A. T., and Connelly, L. (2020). Breast adipocyte co-culture increases the expression of pro-angiogenic factors in macrophages. Front. Oncol. 10:454. doi: 10.3389/fonc.2020.00454

Yuan, C., Zhang, Y., Tu, W., and Guo, Y. (2019). Integrated miRNA profiling and bioinformatics analyses reveal upregulated miRNAs in gastric cancer. Oncol. Lett. 18, 1979-1988. doi: 10.3892/ol.2019.10495

Zografos, E., Zagouri, F., Kalapanida, D., Zakopoulou, R., Kyriazoglou, A., Apostolidou, K., et al. (2019). Prognostic role of microRNAs in breast cancer: a systematic review. Oncotarget 10, 7156-7178. doi: 10.18632/oncotarget.27327

Conflict of Interest: The authors declare that the research was conducted in the absence of any commercial or financial relationships that could be construed as a potential conflict of interest.

Copyright (c) 2021 Delort, Cholet, Decombat, Vermerie, Dumontet, Castelli, Fenaille, Auxenfans, Rossary and Caldefie-Chezet. This is an open-access article distributed under the terms of the Creative Commons Attribution License (CC BY). The use, distribution or reproduction in other forums is permitted, provided the original author(s) and the copyright owner(s) are credited and that the original publication in this journal is cited, in accordance with accepted academic practice. No use, distribution or reproduction is permitted which does not comply with these terms. 